\title{
Quest for the Research!
}

\author{
Ahamed AS* \\ Department of Conservative Dentistry and Endodontics, Rajah Muthaih Dental College and \\ Hospital, India \\ *Corresponding author: A Shafie Ahamed, Department of Conservative Dentistry and \\ Endodontics, Rajah Muthaih Dental College and Hospital, Annamalai University, India, Email: \\ speciality2001@yahoo.com
}

Editorial

Volume 6 Issue 4

Received Date: December 21, 2021

Published Date: December 30, 2021

DOI: 10.23880/oajds-16000319

\section{Editorial}

The law of necessity dictates that "Necessity is the mother of invention!". To find out which treatments work best for patients, research is essential. It is crucial for discovering new treatments and ensuring that existing treatments are used to the best of their ability. Research can provide answers to questions that are unknown, filling knowledge gaps and changing the way health care professionals practice. Research studies are often conducted to diagnose diseases and health problems efficiently, to reduce the number of people who suffer from illness, and to prevent further development or recurrence of the illness. Research studies also aim to treat illnesses to improve patient survival rates or people with illnesses will be cured more often and their quality of life will be improved.

Research is required to develop knowledge. Research is utilized to improve practical approaches. Students learn best when they are actively involved in developing their knowledge through research findings in their field. Teachers use research findings to improve their competence and to improve their teaching and learning process. Innovation may be defined as the process of developing new ideas and then putting them into practice. It demonstrates creativity in problem-solving and produces practical results. Innovative ideas, technologies, or processes are the product of the invention. Millennium development goals have been replaced by sustainable development goals.

Researchers require highly skilled and qualified professionals who can develop systems that can lead the frontiers of technology and understand the global research environment. Research fuels creativity and logical reasoning, enabling the mind to seek answers and promote development.
Global trends must be integrated into institutional research.

Research in its broadest sense involves a careful, diligent search for factual information. It is a systemic investigation of a situation to generate new knowledge or validate the information that already exists. Research plays an important role in developing an efficient learning process. It assists in building fundamental knowledge, providing information, correcting false perceptions, and fostering critical thinking. Researchers can use this to determine whether an idea is supported by previous studies or needs to be verified before it is deemed knowledge. Research leads to a better understanding of issues. Research uncovers unknown issues; questions that were not considered may arise, which can help academics achieve strong credibility.

The term knowledge is often used to describe factual proportions in the mind of an individual. Facts are derived from objective insights and/or study findings and quantified by the brain. In addition to reading and watching articles and books, listening to experts and watching documentaries and investigative shows, conducting experiments, and interacting with people, there are many ways to acquire this knowledge. The truthfulness and accuracy of facts collected during research can be confirmed by checking them with other sources.

As a rule, inductive approaches are associated with qualitative research, while detective techniques are associated with quantitative research. An inductive method analyzes an observed event, but detective methods verify it. The purpose of research is to establish a theory, hypothesis, or fact. Research can also be used to disprove what was believed to 
be the truth. It may be used to obtain precise information that will aid in better understanding an issue. Getting acquainted with research articles in journals enables us to improve our reading and writing skills. Additionally, it enhances our analytical, listening, and speaking capabilities. All of these functions improve our comprehension and computation skills. To evaluate a research journal's credibility, several key factors need to be considered: the journal must be included or indexed in the major bibliographic database, articles must be discoverable, its history of publication, the journal's mission, the members of the editorial board, time frame for peer- review and finally the impact factor. An impact factor is a measure of the average number of citations a journal gets over two years. Our journal has a very good goal for what it is, has a good reputation in the field of research, and publishes innovative articles for a long time. Members of our editorial board are highly regarded in their fields of research, making our journal appear more credible with its great indexing and high impact factor. 